\title{
Innovation through Emergence of Technology Communities: Some Management Lessons
}

\author{
Vinnie Jauhari \\ Institute for International Management and Technology, Gurgaon, India
}

\begin{abstract}
Networks play a key role in developing next generation innovations. Technology led innovations are led by technology developers and communities.

There is an evidence of success of innovations in technology development through networking with technology communities. Some of these are formal networks and some of these are informal networks. This paper explores at some of the successful developments in the technology domains such as development of Android applications and I-phone applications. Each of these interventions involved collaborations between academic communities, corporate firms as well as independent technical professionals. The success of Apple and Android communities opens up many new research questions as both the organizations have followed a very different approach in developing new technologies. Android which is developed by Google has followed a different approach as compared to development of Apple applications. The paper would throw insights into these approaches.

Some of the technology communities had a more open approach and some of the communities have a more closed approach. This paper documents the differences in approaches of development of these communities.

The paper is a qualitative study which provides an insight into the differences in approach of development of select technology communities. The paper also draws leadership lessons and factors which contribute to the success of such initiatives. The paper assesses the challenges that these firms faced in developing such communities.
\end{abstract}

Keywords: Android, Apple, Closed innovation, Google, IOS, Open innovation, Technology communities.

\section{INTRODUCTION}

$\mathrm{N}$

etworks are playing a role like never before in facilitating innovation. As technology goes through huge changes, there is an impact on the emergence of new models. The last decade has seen emergence of many new technologies that has opened doors to many new business forms and approaches. The emergence of facebook, cloud computing, You Tube, Skype, Android, Share Point throw open many lessons in management, strategy and leadership. More importantly these initiatives demonstrate the role of communities and technology in transforming ordinary and simple ideas into

Journal of Technology Management for Growing Economies Vol. 3 No. 2 October 2012 pp. 89-103 CHITKARA

(C)2012 by Chitkara University. All Rights Reserved. 

interesting questions and insights into how the consumer markets are evolving. It also throws open a debate on what are the key value drivers for such growth and what kind of technologies and business approach is faciliting this growth. Mobile applications are the most important factor in driving the sales of smart phones (Datamonitor Report on Apple Inc). Total mobile application market will be approximately \$9billion by 2014 (Datamonitor report on Apple Inc).Consider some statistics from Gartner which mentions that "ad revenue would generate USD 600 million globally. Worldwide downloads in mobile app stores will surpass 21.6 billion by 2013. Free downloads will account for $87 \%$ of downloads in 2013." (Euromonitor, 2010). The two fastest growing categories of smartphones are led by technology platforms driven by Android (Google) and iOS (Apple).It would be interesting to understand how these two technology platforms got developed and to track the similarity and differences in the approach of these two technology communities.

\section{Objective of the Study}

This paper discusses the role of technology communities in emergence of select initiatives - Android and Apple communities. The management lessons have also been delved upon. The paper also raises research questions in the domain of managing these technology communities.

\section{Approach for Conducting This Research}

It is a qualitative and an exploratory study which tracks how Android and Apple technology communities emerged. The basis of this research is analysis of secondary data and experiences in developing technology communities during my work at HP Labs. Several studies have been assessed to identify the parameters of comparison between emergence of technology communities. The study also involved unstructured discussions with users of Android and applications developed by Apple.

\section{Review of Literature}

One of the key changes that the changes in information technology has triggered is the convergence of communication and computing technologies. This has led to emergence of many new products such as smart phones. These new gadgets act as multiple devices and carry an enormous capability for information access and communication made possible through many new distinctive technologies. The multiplicity of use of the same device has led to emergence of a technology platform strategy which could be adopted by various firms. The emergence of new technology platforms such as Android 
or iOS offer very distinctive strategic insights into various approaches could be adopted to create distinctive user experiences. The approach of developing product or service offerings could be very different yet the outcomes could be very similar. Technology communities are enablers and developers of new innovations (Jauhari \& Benard, 2010). They may emerge in a same organization or from different organizations. "Open innovation is a purposive flow of inflows and outflows of knowledge to respectively, accelerate internal innovation and expand the market for external use of innovation," (Chesbrough, et. al., 2006, pg.1) (cited in Van de Vrande et. al., 2009). There is a huge debate in management literature in the last few years on the scope and implementation of the open innovation approach. Enkel et. al., 2009) have also delved upon the concept of open innovation. This involves the following two key components:

- "The outside-in process: enriching the company's own knowledge base through the integration of suppliers, customers, and external knowledge sourcing.

- $\quad$ "The inside-out process refers to earning profits by bringing ideas to market, selling IP, and multiplying technology by transferring ideas to the outside environment. Creating new spin offs and also splitting businesses could be a part of this process.

Fichter (2009) remarks, "Open innovation has to date not been well connected to insights from research on the role of transformational leaders and the networking of champions and promoters across organizational boundaries". Fichter (2009) defines innovation communities as "an informal network of like minded individuals acting as a universal or specialized promoters often from more than one company and different organizations that team up in a project related fashion and commonly promote a specific innovation either on one or across different levels of an innovation system".

The emergence of technology or innovation communities is a manifestation of open innovation approach. There has been a lot of research in the domain of open innovation. One of the key champions of open innovation approach has been Chesterbrough. Open innovation is about working with internal and external stakeholders for innovation. It is about networking with external stakeholders such as universities, suppliers, government, customers to develop and build new ideas and advance technologies. However, at what level these external engagements are taken to would vary from company to company. The strategy could
Innovation through

Emergence 
be very open as in case of development of Linux or Wikipedia. It could be more controlled as in case of Apple which works with external communities to develop Apps for its devices. Chesbrough \& Appleyard (2007) have discussed the concept of open strategy which balances the tenets of traditional strategy with the promise of open innovation. It embraces the openness as a means of expanding value creation for organizations. It also introduces new business models based on invention and coordination undertaken within a community of innovators. It would be important to understand that in the context of mobile platforms, there are several aspects which contribute to emergence of these platforms. Wikhamn et. al. (2011) have discussed the characteristics of a mobile platform. These are: infrastructure hardware, software applications, developers of technology platforms, operation system, user interface and applications, network, service providers, mobile portal providers. Wikhamn et. al. (2011) discuss the concept of generativity rather than openness that drives a platform's aggregated wealth. Generativity as defined by Wikhamn et. al. (2011) is, "a technology's capacity to enable voluntaristic and spontaneous innovation driven by large, heterogeneous and uncoordinated crowds of people (Zittrain, 2006; 2009)". They also discuss various parameters on which the generativity of a technology platform can be assessed. These are:

Leverage: Degree to which a technology helps in performing certain tasks.

Adaptability: How flexible and modifiable the technology is in performing the tasks?

Ease of Mastery: How is technology used?

Accessibility: How easy is technology accessed?

Transferability- How easily is the technology updated and distributed?

Grotnes (2009) has introduced the concept of anticipatory standardization. He defines, "anticipatory standardization as future capabilities in contrast to recording and stabilizing existing practices or capabilities defacto (Lyytinen et al, 2008). Standardisation has gone from a process where the market or an organization chooses between different existing products in hindsight to a process where companies pool their resources together to create new products and servicesanticipatory standardization".

Gower and Cusumano (2008) have discussed two very distinct strategies which could lead to developing successful technology platforms. These are coring and tipping. "Coring is a set of activities a company can use to identify or design an element (a technology, a product or a service) and make this element fundamental to a technological system as well as to a market" (Gower and Cusumano, 2011). They have cited example of Google as an 
example of deploying coring as a key strategy. "Tipping is set of activities or strategic moves that companies can use to shape market dynamics and a win a platform war when at least two platform candidates compete. These moves cover sales, marketing, product development and coalition building" (Gower and Cusumano, 2011). They have cited Linux as an example of tipping strategy. They have cited example of Google as an example of deploying coring as a key strategy. Their work has also suggested dimensions on which various technology communities could be classified and also strategies which successful technology leaders have been deploying:

1. Balance between in-house activity and external collaboration

2. Controlling the design of technology and managing the intellectual property rights

3. Managing the relationships with the various stakeholders

4. Effectively managing the internal organization structures

Variables for Comparison of the two technology communities.

The review of literature reveals several variables which could be considered as a basis of comparison:

1. Objective of developing a technology community: what are the reasons to set up the community.

2. Approach towards developing the technology community.

3. Business model: How is the technology community organized and whatv is the revenue model?

4. What are the outcomes of the work of the technology community?

5. What is the approach towards developing the technology? Is the approach open or closed? What would be the level of control exerted by the promoters of the community? Who plays a bigger role?

6. What are the characteristics of the technology platform? What is the key philosophy behind the developmental effort?

7. What are the motivations in the community which work towards devel oping the technologies?

8. Organisation and production of the outcomes: This assessed how the whole process of development is structured and how is the production commercialized.

The next two sections give some insights into Apple and development of iPhone and Android Technology community. The differences in their approach has been summed up in Table 1 based on secondary research. 
Apple has been named as the world's most admired company by Fortune Magazine for the 5th year in a row. Apple also ranks first in Innovation category (Apple, 2012). The advent of iphone, ipad and App store has reshaped the mobile phone market bringing commercial and brand success in their effort to challenge developers, suppliers and vendors of mobile phones and mobile applications with new technological platforms (Wikhamn etal, 2011). Gassmann et. al. (2010) have enumerated on the role of inter-organizational networks which could lead to value creation. They have cited the example of development of Apple i-Pod wherein the an external entrepreneur Tony Fadell developed the idea and the concept. Apple hired a 35 person team and partners from Phillips, Ideo, General Magic, Apple, Connectix and Web TV to develop the ipod system. The technical design was managed by Portal Playera Wolfson, Toshiba and Texas instruments alliance.

Apple as a company is engaged in design, development and marketing of personal computers, media devices and portable digital music players. The company also sells a variety of related software, services, peripherals, networking solutions and third party digital content and applications. The company's portfolio of offerings comprises Macintosh computing systems, iPods line of portable digital music and video players, iPhone handsets and iPad portable multimedia and computing devices. The company primarily operates in US, headquartered in Cupertino, California and employs 46,600 employees. The company recorded revenues of $\$ 65,225$ million during the financial year ended in September 2010 (Datamonitor, 2011).

The iOS and its various versions offer a wide variety of applications. iOS 5 includes more than 200 new features for iPad, iPhone, or iPod touch. iCloud is so much more than a hard drive in the sky. It makes it quick and effortless to access just about everything on the devices that one uses every day. iCloud automatically and securely stores the content so it's always available on iPhone, iPad, iPod touch, Mac, or PC. It gives an individual access to their music, movies, apps, latest photos, and more from whichever device one happens to be using. And it keeps ones email, contacts, and calendars up to date across all the devices. No syncing is required.

iCloud stores music, photos, documents, and more and wirelessly pushes them to all Apple devices. The products produced by Apple and the applications and experience has led to a steadily growing market share across various segments. Apple announced on March 31,2012 that more than 25 billion apps have been downloaded from its App Store by the users of morethan $315 \mathrm{mn}$ iPhone, iPad and iTouch devices world-wide. App store owned by Apple offers 
550,000 apps to iPhone, iPad and iPod Touch users in 123 countries across areas such as newsstand, games, business, news, sports, health and fitness, travel. For developing these apps, Apple Store has paid out more than \$4billion to developers. Apple launched iCloud to enable seamless data transfer through various devices. This provides access to individual data across various Apple devices.

Vogelstein (2008) in his article written for wired.com has given insights into iphone was developed. Steve Jobs and his R\&D teams had to work on numerous elements both the hardware, software and also had to look at external relationships with the telecom giant AT\&T to be iPhone's carrier. The following paragraph shows the effort and networking with external and internal stakeholders that led to the development of I phone both as a device and a remarkable operating system. The company's R\&D expenditure \$1782 million, \$1333 million and \$1109 million in FY 2010, 2009, 2008.

"In return for five years of exclusivity, roughly 10 percent of iPhone sales in AT\&T stores, and a thin slice of Apple's iTunes revenue, AT\&T had granted Jobs unprecedented power. He had cajoled AT\&T into spending millions of dollars and thousands of man-hours to create a new feature, so-called visual voicemail, and to reinvent the time-consuming in-store sign-up process. He'd also wrangled a unique revenue-sharing arrangement, garnering roughly $\$ 10$ a month from every iPhone customer's $A T \& T$ bill. On top of all that, Apple retained complete control over the design, manufacturing, and marketing of the iPhone. Jobs had done the unthinkable: squeezed a good deal out of one of the largest players in the entrenched wireless industry. The company nets an estimated $\$ 80$ for every $\$ 399$ iPhone it sells, and that's not counting the \$240 it makes from every two-year AT\&T contract an iPhone customer signs. Meanwhile, about 40 percent of iPhone buyers are new to AT\&T's rolls, and the iPhone has tripled the carrier's volume of data traffic in cities like New York and San Francisco".

So, in early 2006, just as Apple engineers were finishing their yearlong effort to revise OS X to work with Intel chips, Apple began the process of rewriting OS X again for the iPhone. The conversation about which operating system to use was at least one that all of Apple's top executives were familiar with. They were less prepared to discuss the intricacies of the mobile phone world: things like antenna design, radio-frequency radiation, and network simulations. To ensure the iPhone's tiny antenna could do its job effectively, Apple spent millions buying and assembling

Journal of Technology Management for Growing Economies, Volume 3, Number 2, October 2012
Innovation through Emergence 
special robot-equipped testing rooms. To make sure the iPhone didn't generate too much radiation, Apple built models of human heads - to simulate brain density - and measured the effects. To predict the iPhone's performance on a network, Apple engineers bought nearly a dozen server-sized radio-frequency simulators for millions of dollars apiece. Even Apple's experience designing screens for iPods didn't help the company design the iPhone screen, as Jobs discovered while toting a prototype in his pocket: To minimize scratching, the touch screen needed to be made of glass, not hard plastic like on the iPod. One insider estimates that Apple spent roughly $\$ 150$ million building the iPhone".

Source: Vogelstein(2008) in wired.com

The financial results of Apple in the second quarter ending March 31, 2012 is as below:

Quarterly revenue $\$ 39.2 \mathrm{bn}$

Quarterly net revenue $\$ 11.6 \mathrm{bn}$

Gross margin

$\$ 47.4 \%$

Apple sold 35.1 million phones in a quarter which was $88 \%$ higher than the same quarter in2011. It sold 11.8 million ipads, $7.7 \mathrm{mn}$ ipods, $4 \mathrm{mn}$ Macs in the quarter ending March 31st, 2011. Apple has been a gatekeeper of applications developed by the external community. It takes the final call on the upload of the application through its OS. It also keeps a very tight control on the design elements and offers a unified approach linking its product line. It collaborates with external stakeholders but in a very well defined and a systematic manner and controls what reaches out to the consumer.

\section{Emergence of Android Community}

Android is an open-source software stack created for mobile phones and other devices. The Android Open Source Project (AOSP), led by Google, is tasked with the maintenance and further development of Android. Many device manufacturers have brought to market devices running Android, and they are readibly available around the world.

The primary purpose for the community is to build an excellent software platform for everyday users. A number of companies have committed many engineers to achieve this goal, and the result is a full production quality consumer product whose source is open for customization and porting.

Android was originated by a group of companies known as the Open Handset Alliance, led by Google. Today, many companies — both original members of the OHA and others - have invested heavily in Android, typically in the form of allocating significant engineering resources to improve Android

Journal of Technology Management for Growing Economies, Volume 3, Number 2, October 2012 
and bring Android devices to Market. On 5th Nov 2007, the Open Handset Alliance was made public. OHA is a consortium around 50 companies from mobile phone industry including leading operators, handset manufacturers, semiconductor firms, software developers and commercial vendors with a shared goal to develop open standards for mobile devices.

Android wanted to make sure that there would always be an open platform available for carriers, OEMs, and developers to use to make their innovative ideas a reality. It is based on open source. The goal of the Android Open Source Project is to create a successful real-world product that improves the mobile experience for end users.

Android is a mobile software platform which is a big challenge for Apple iOS, Nokia's Symbian and Microsoft's Windows OS. Android powers 135 million active devices across the world after its 2008 launch and commands a $46 \%$ marketshare in platforms. Symbian has slipped to 22\%.(Hindustan Times, 2011).

\section{Governance Philosophy}

The companies that have invested in Android have done so on its merits, because they believe that an open platform is necessary. Android is intentionally and explicitly an open-source - as opposed to free software - effort: a group of organizations with shared needs has pooled resources to collaborate on a single implementation of a shared product. The Android philosophy is pragmatic, first and foremost. The objective is a shared product that each contributor can tailor and customize.

Uncontrolled customization can, of course, lead to incompatible implementations. To prevent this, the AOSP also maintains the Android Compatibility Program, which spells out what it means to be "Android compatible", and what is required of device builders to achieve that status. Anyone can (and will!) use the Android source code for any purpose, and we welcome all such uses. However, in order to take part in the shared ecosystem of applications that we are building around Android, device builders must participate in the Compatibility Program.

Along with many partners, Google has contributed full-time engineers, product managers, UI designers, Quality Assurance, and all the other roles required to bring modern devices to market. We roll the open source administration and maintenance into the larger product development cycle.

- At any given moment, there is a current latest release of the Android platform. This typically takes the form of a branch in the tree.

- Device builders and Contributors work with the current latest release, fixing bugs, launching new devices, experimenting with new features, and so on.

Journal of Technology Management for Growing Economies, Volume 3, Number 2, October 2012
Innovation through Emergence 
Jauhari, V.
- In parallel, Google works internally on the next version of the Android platform and framework, working according to the product's needs and goals. We develop the next version of Android by working with a device partner on a flagship device whose specifications are chosen to push Android in the direction we believe it should go.

- When the " $n+1$ "th version is ready, it will be published to the public source tree, and become the new latest release.

\section{Analysis of Approaches of iOS Developed By Apple for iphone and other Apple Devices and Android Technology Communities}

The analysis of application communities for developing Apple applications and Android Applications is summed up in Table 1. These comparisons are on two very different approaches. Both the approaches are very strong on innovation and demonstrate the ability to work with variety of stakeholders. In case of Apple, though a very vibrant external technology ecosystem of developers exist but the whole process is tightly controlled and Apple acts as a gatekeeper for the applications which are emanating out. For Android, the key stakeholders are multiple firms but Google is a key champion. "Android depends on third party application developers to create applications that makes it standout from other operating platforms /systems. The goal of the Open Hanset Alliance is to sell more morehandsets based on Android platform though the availability of new and innovative applications. The hope is that Andorid platforms will create higher overall value than the competitors will, so operators, manufacturers and application vendors will be attracted to the platform" (Grotnes, 2009).

Table 1: Comparison of Two Technology Community Approaches

\begin{tabular}{|l|l|l|}
\hline \multicolumn{1}{|c|}{$\begin{array}{c}\text { Variable for } \\
\text { Comparison }\end{array}$} & \multicolumn{1}{|c|}{ iPhone Community } & \multicolumn{1}{c|}{ Android Community } \\
\hline Stakeholders & $\begin{array}{l}\text { Mobile Phone industry (Apple, } \\
\text { vendors, operators, users, applica- } \\
\text { tion users and developers }\end{array}$ & $\begin{array}{l}\text { Mobile phone industry (Dif- } \\
\text { ferent Manufacturers vendors, } \\
\text { Operators, users, application } \\
\text { users and developers }\end{array}$ \\
\hline $\begin{array}{l}\text { Core of the tech- } \\
\text { nology platform }\end{array}$ & $\begin{array}{l}\text { iOS which is unique to Apple } \\
\text { devices }\end{array}$ & Development on Linux Kernel \\
\hline Applicability & Only Apple devices & $\begin{array}{l}\text { Can be deployed by various } \\
\text { hardware manufacturers and also } \\
\text { embedded devices. Samsung, } \\
\text { HTC, Motorola, LG, Sony } \\
\text { have been some of deployers of } \\
\text { Android platform in their mobile } \\
\text { devices. }\end{array}$ \\
\hline
\end{tabular}

Journal of Technology Management for Growing Economies, Volume 3, Number 2, October 2012 


\begin{tabular}{|c|c|c|}
\hline $\begin{array}{l}\text { Variable for } \\
\text { Comparison }\end{array}$ & iPhone Community & Android Community \\
\hline $\begin{array}{l}\text { Mobile Applica- } \\
\text { tions }\end{array}$ & $5,50,000$ as on March 31,2012 & $\begin{array}{l}\text { 450,000 applications (http://dot- } \\
\text { tech.org/android/android-apps- } \\
\text { of-the day/29601/android-apps- } \\
\text { of-the-day-march-31-2012/) }\end{array}$ \\
\hline Market & $\begin{array}{l}150,000 \text { iPhones are activated } \\
\text { daily }\end{array}$ & $\begin{array}{l}350,000 \text { Android smart phones } \\
\text { are activated daily }\end{array}$ \\
\hline $\begin{array}{l}\text { Variable for } \\
\text { comparison }\end{array}$ & iOS & Android \\
\hline $\begin{array}{l}\text { Dynamics of } \\
\text { external market }\end{array}$ & $\begin{array}{l}\text { Intensely competitive-Apple has } \\
\text { to complete with eminent firms } \\
\text { such as Microsoft, HP, Samsung, } \\
\text { Sony, LG, Toshiba }\end{array}$ & $\begin{array}{l}\text { Fastest emerging mobile OS for } \\
\text { OEMs such HTC, Samsung, } \\
\text { Sony, Motorola }\end{array}$ \\
\hline Leverage & $\begin{array}{l}\text { Standardized offering through } \\
\text { standardized hardware-iphone, } \\
\text { ipad, ipod touch }\end{array}$ & $\begin{array}{l}\text { Several handheld manufactur- } \\
\text { ers work separately and jointly. } \\
\text { There is customization with } \\
\text { different vendors and various } \\
\text { applications could be created or } \\
\text { adopted by various manufac- } \\
\text { turers such as Samsung, HTC, } \\
\text { Sony, LG. }\end{array}$ \\
\hline Adaptability & $\begin{array}{l}\text { There are various applications } \\
\text { available for games, entertain- } \\
\text { ment, utilities, navigation etch but } \\
\text { on Apple various devices }\end{array}$ & $\begin{array}{l}\text { There are various applications } \\
\text { available for games, entertain- } \\
\text { ment, utilities, navigation etch } \\
\text { but on various devices }\end{array}$ \\
\hline Control & $\begin{array}{l}\text { Apple has a full control over the } \\
\text { hardware, software, os, graphic } \\
\text { user interface, and the handheld } \\
\text { device }\end{array}$ & $\begin{array}{l}\text { This os is integrated with vari- } \\
\text { ous handheld devices and could } \\
\text { be adapted depending on the } \\
\text { features a manufacturer would } \\
\text { like to deploy. }\end{array}$ \\
\hline Approach & $\begin{array}{l}\text { The programming language is } \\
\text { primarily objective C. There are } \\
\text { standard toolkits available, frame- } \\
\text { works, SDK kits, development } \\
\text { practices are shared, technical } \\
\text { documents are shared and guides } \\
\text { for creating applications are } \\
\text { shared. }\end{array}$ & $\begin{array}{l}\text { There are standard kits avail- } \\
\text { able for android. The system is } \\
\text { more accessible and open. Open } \\
\text { source platform is deployed. } \\
\text { Java as a programming language } \\
\text { is deployed. Most of the system } \\
\text { code is revealed as open source. } \\
\text { Linux kernel is used as a base. }\end{array}$ \\
\hline $\begin{array}{l}\text { Payment Sys- } \\
\text { tems }\end{array}$ & $\begin{array}{l}\text { Straightforward payment systems } \\
\text { and well established distribution } \\
\text { network. }\end{array}$ & \\
\hline Retailing & $\begin{array}{l}\text { Online and brick mortar Apple } \\
\text { stores have been created for } \\
\text { download of apps and other Apple } \\
\text { devices. }\end{array}$ & $\begin{array}{l}\text { There is an Android Play - an } \\
\text { online retail store. }\end{array}$ \\
\hline
\end{tabular}

Innovation
through
Emergence

99 

such as Android website, Apple website, Grotnes (2009), Datamonitor Report on Apple, Wikhamn et. al. (2011).

\section{Conclusion}

Android and iPhone community are both examples of huge success and growing market shares. They are also competing for a bigger space in consumer's mind. Apple's approach is more closed and the applications are all targeted towards its own product line which has been accepted very well by the global consumers. Android has a more open approach but is deployed by various handheld manufacturers. There are specific lessons which could be drawn based on the experience of both the communities.

The biggest reason for Apple's success is a very distinctive user experience that has been created through the precipitation of outstanding design features, a very functional software, portability and a dynamic approach in creating applications managed on a cloud which enables portability of data across devices produced by the same brand. All this is visible through the growing market shares and profitability generated by Apple. The company has controlled its internal $R \& D$ and has fostered strategic alliances with numerous stakeholders. Though apple has fostered open innovation approach with external technology community to develop iphone applications yet it is closely monitored. Apple acts as a gatekeeper for the forms that these application take.

Innovation is also taking new forms. Auctioning of patents, developing new technologies and software applications, moving to open source domains are all examples of new ways of innovation (Euromintor, 2010). Consumption will get more personal and it is widely expressed through the link between mobile technologies and social networks.

There is enormous power in the hands of handheld devices if they deploy appropriate technology platforms. The future of these technology platforms can spark huge contribution from technology members. If there is recognition for their work, appropriate organization structures are created and suitable financial and professional recognition is in place, it can create amazing outputs as has been seen both in cases of Android and Apple communities. The motivations for these communities could be both intrinsic and extrinsic. Firms have to see they continuous keep their community members engaged and motivated.

The technology communities could have very different motivations. In case of Android, it is the success of the platform which will drive growth 
for all stakeholders. In case of Apple, it is a unified approach of a seamless

Innovation integration between its devices and a computing power in a cloud which will through drive the next level of growth. In case of Apple the revenues are coming in Emergence from excellently designed hardware and assimilation of software coupled with new and vibrant applications. In case of Google, the revenues come in primarily from the advertisements in search engine space. However, Android as a operating system deployed by various handheld devices will lead to what level of profitability is yet to be seen.

\section{Research Questions for Future Studies}

The exploratory study of both the communities open up interesting research questions which could be explored in future studies.

1. Which approach would be more appropriate - a more controlled open approach adopted by Apple Inc. or relatively loosely federated open approach as adopted by Android community?

2. What are the contextual elements on which the performance of the technology communities can be measured? Are some of these elements more influential in the success of these communities?

3. What are differences in approach of development of these communities?

4. What are the motivations which keep these technology community together?

5. What kind of business models should emanate out of these models? Are these sustainable over longer periods? What are the lessons learned from the examples of Android and Google experiences?

6. What organizational factors lead to the success of such initiatives?

7. What are the key challenges faced by these technology communities?

8. What kind of factors lead to emergence of such technology communities? What is the business and government context which leads to such developments?

9. What is the role of private sector, government, R\&D institutions and universities which facilitate the emergence of such technology communities?

10. What are the leadership lessons learned from such technology communities?

11. What aspects of technology platforms become enablers of value creation? 


\section{REFERENCES}

Android (2012) About the Andorid Open Source Project Downloaded from http://source. android.com/ about/index.html on June 9, 2012.

Apple (2012) Apple's App Store Downloads Top 25 Billion, March 5th, Downloaded from www.Apple.com/in/hotnews on June 10, 2012.

Apple (2012) Apple World's Most Admired Company, March 1. Downloaded from www. Apple.com/in/hotnews on June 9, 2012.

Chesbrough, Henry and Appleyard, M.M. (2007) Open Innovation and Strategy, California Management Review, 50(1).

Datamonitor (2011) Apple Inc. Company Profile, Oct.7, 2011 Downloaded from www.datamonitor.com.

Enkel, E. (2010) Attributes Required for Profiting from Open Innovation In Networks, International Journal of Technology Management (in press).

Enkel, E., Gassmann, O. and Chesbrough, H. (2009) Open R\&D and Open Innovation: Exploring the Phenomenon, R\&D Management, Vol. 39(4), 311-316.

Economic Times, (2012) Apple Crushes St Targets, Dispels iPhone Fears, Economic Times, April 26, p. 20.

Euromonitor International (2010) Smartphones: Not Just iPhones but a Boomrang Movement, March 10.

Fichter, K. (2009) Innovation Communities: The Role of Networks of Promotors in Open Innovation, R\&D Management, 39:4, 357-371.

Oliver Gassmann, O., Enkel, E. and Chesbrough, H. (2010) The Future of Open Innovation, R\&D Management, 40:3, 213-221.

Gawer, A. and Cusumano, M.A. (2008) How Companies Become Platform Leaders, MIT Sloan Management Review, 49:2, 28-35.

Gold, S. (2012) Android A Secure Future at Last? Engineering and Technology, March, 50-54.

Grotnes, E. (2009) Standardization as Open Innovation: Two Cases from Mobile Industry, Information Technology and People, 22:4, 367-381.

Hindustan Times (2011) Is Android the New Windows, HT Business, Hindustan Times, August 20,25-26.

Jauhari, Vinnie and Michel Benard (2010) University Industry Collaboration: An Open Innovation Approach at Hewlett-Packard, Journal of Technology Management for Growing Economies, 1:1, 23-33.

Van de Vrande, V., De Jong, J., Vanhaverbeke, W. and De Rochemount, M. (2009) Open Innovation in SMEs: Trends, Motives and Management Challenges, Science Direct, Technovation, 29:6/7, 423-437.

Vogelstein, Fred, (2008) The Untold Story: How the iPhone Blew Up the Wireless Industry, Wired.com Downloaded from http://www.wired.com/gadgets/wireless/magazine/16-02/ff_iphone?current Page=all Downloaded on June 10, 2012 at $11.38 \mathrm{hrs}$.

Wikhamn, B.R., Ljungberg, J., Bergquist, M. and Kuschel, J. (2011) Open Innovation, Generativity and the Supplier as a Peer: The case of IPhone and Android', International Journal of Innovation Management, 15(1), February, 205-230.

Zittrain, J. (2006) The Generative Internet, Harvard Law Review, 119, 1975.

Journal of Technology Management for Growing Economies, Volume 3, Number 2, October 2012 
Zittrain, J. (2008) The Future of Internet and How to Stop It, Yale University Press, New Haven CT.

Vinnie Jauhari, is Director, Institute for International Management and Technology, Gurgaon, India. Email: vjauhari@iimtobu.ac.in.

This paper was presented by the author at, "Twelfth Global Conference on Flexible Systems Management- Systemic Flexibility and Business Agility, July 30-August 1, 2012 University of Vienna, Vienna, July 30-August 1, 2012."
Innovation through Emergence . 